\title{
Sonhos e concretudes em territórios de vulnerabilidade social latente: altruísmo na gestão escolar
}

Mestre em Educação e Saúde na Infância e na Adolescência pela Unifesp, diretora de escola na Rede Municipal de Ensino de São Paulo

E-mail: silvana_pacheco@ ig.com.br
Resumo: 0 artigo tem por objetivo relatar prática de gestão desenvolvida em uma escola municipal na periferia de São Paulo, região de alta vulnerabilidade social. A experiência visou o envolvimento de todos os funcionários e da comunidade no processo educativo. O texto analisa a implantação de uma proposta de gestão diferenciada da tradicional, que caminha na contramão de algumas normas que, avalia-se, inviabilizam o sucesso da gestão educacional como um todo. Apresenta aspectos que retratam divergências entre escolas e comunidades. Salienta que para a consecução de um trabalho coletivo não tradicional na escola de território vulnerável é necessária uma equipe concatenada e proativa em busca de boas relações interpessoais. Busca mostrar que é possível construir, gerir e administrar a educação visando a dignidade humana das pessoas.

Palavras-chave: Gestão democrática. Protagonismo. Vulnerabilidade social. 


\section{INTRODUÇÃO}

Relatar em poucas palavras o trabalho que se desenvolve há alguns anos numa escola pública da periferia da zona leste da cidade de São Paulo, eis o desafio.

Este artigo apresenta, com a relatividade e brevidade necessárias, o trabalho realizado em uma escola pública municipal localizada no extremo leste da cidade de São Paulo, região de alta vulnerabilidade e exclusão social. Considerada pela população local como a melhor escola do bairro, enfrenta o problema da demanda preferencial, o que representa satisfação e reconhecimento àqueles que trabalham na escola e frustração às famílias que não conseguem uma vaga.

Atualmente atende cerca de mil alunos do ensino fundamental, incluindose neste total alunos com necessidades educacionais especiais de diversas especificidades. Funcionando em dois turnos diurnos, das $7 \mathrm{~h}$ às $18 \mathrm{~h} 30$, a escola tem aproximadamente 90 funcionários, sendo a maioria professores, entre 60 e 70, compondo-se o total com funcionários administrativos e operacionais. Desde 1999 atuando na unidade escolar e incentivando a realização de projetos e ações voltadas aos interesses dos alunos e da comunidade, pôde-se notar alguns avanços e o envolvimento dos alunos como fatores que contribuem para a concretização de uma escola de qualidade.

O artigo relata a prática de gestão compartilhada que se exerce nesta unidade escolar, visando a implantação da gestão integrada e integradora, que valoriza sempre o trabalho em equipe, com a participação de toda a comunidade escolar em diversos espaços criados especificamente para este fim, como o Conselho de Escola, as reuniões semanais da equipe técnica, as reuniões com representantes de sala eleitos por seus pares e a formação permanente e continuada com professores e funcionários no horário de trabalho.

$\mathrm{Na}$ prática de gestão compartilhada, busca-se incentivar sempre 0 protagonismo de todos os envolvidos, os funcionários em suas respectivas áreas de atuação, os alunos em projetos de monitoria, as famílias nos encontros promovidos periodicamente pela escola, no Conselho de Escola e Associação de Pais e Mestres (APM) e os professores na elaboração coletiva dos projetos da escola.

Discutir as implicações de se implantar uma proposta de gestão democrática, compartilhada, que envolva e responsabilize todos e cada um no processo 
representa um desafio, já que está na contramão da história da gestão autocrática, cujo poder é centralizado nas mãos do diretor da escola e de um sistema burocrático que inviabiliza a ação autônoma da escola, prevista na Lei de Diretrizes e Bases da Educação Nacional (LDB), o que pode comprometer o sucesso da gestão educacional como um todo.

Salienta-se que para a consecução de um trabalho coletivo não tradicional e inovador na escola em território vulnerável é fundamental uma equipe concatenada, proativa e que supere os individualismos em busca de boas relações interpessoais, da superação dos conflitos e colabore com a melhoria da qualidade dos serviços prestados, tendo como consequência contribuir para a formação de cidadãos que protagonizem ações sociais de mudança da realidade e do contexto em que vivem.

Este artigo apresenta aspectos que retratam divergências entre a lógica dos pontos de vista escolar e das famílias, que precisam sem superadas e compreendidas, pois as duas instituições são responsáveis pelo processo de socialização e educação de crianças e adolescentes. Tempos e espaços escolares não convergem com tempos e espaços familiares, assim como não convergem com os aspectos legais que organizam o sistema. Entretanto, as três instâncias se inter-relacionam simultaneamente, de modo que é preciso dialogar e enfrentar os desafios de construir uma escola e uma educação diferenciadas nos territórios vulneráveis.

Finalmente o artigo se encerra afirmando que é possível construir, gerir e administrar a educação visando a dignidade humana das pessoas, por meio de propostas diferenciadas e singulares, construindo-se educação de qualidade a partir da perspectiva que considera as necessidades e pontos de vista do contexto socioespacial em que a escola está inserida.

A grande complexidade do que se denomina educação escolar torna 0 pensar a gestão da instituição escolar algo não menos complexo, que se reveste de desafios permanentes de diferentes naturezas e razões, todos eles fundamentais no processo de pensar e construir uma escola pública de qualidade para todos, o que, segundo Azanha (1995), tem sido pensado muitas vezes de forma excessivamente simplificada.

Falar sobre educação de qualidade para todos pode parecer demagógico, redundante e até utópico, afinal, este é um discurso recorrente desde o advento de implantação da escola "Para todos" no Brasil e no mundo. "Ela [a escola] trazia, portanto, promessas de justiça a um mundo socialmente 
desigual" (DUBET, 2008, p. 23), ou o sonho de um mundo melhor que de fato não se concretizou para todos, mas que tem garantido ao longo da história a evolução das condições objetivas e materiais de existência daqueles que a ela tiveram acesso. Pesquisas desenvolvidas em países da Europa afirmam que o percentual suplementar de salário em relação direta com os anos de escolaridade obtidos pode chegar à "ordem de oito a dez pontos" (BAUDELOT; LECLERC, 2004' ${ }^{1}$; apud DUBET, 2008, p. 97). Entretanto, não se pode assumir o exercício da função pública, na gestão escolar, sem a clareza necessária dos compromissos que envolvem a atuação na instituição escolar.

A Lei de Diretrizes e Bases da Educação (LDB) e orientações normativas Vulnerabilida grupos e com intensidades. a fragilidade institucional realizar as $m$ apresenta; $a \mathrm{i}$ incentivam o exercício da autonomia escolar na elaboração do projeto político(BUSSO, 2001 pedagógico, mas estabelecem procedimentos de organização e funcionamento da estrutura escolar, através de portarias, decretos e comunicados, que muitas vezes engessam a suposta autonomia, inviabilizando, dificultando e tornando as ações escolares vulneráveis a interferências externas, dependentes das condições financeiras e dos recursos humanos disponíveis (MARTINS, 2002).

No entanto, envidar esforços para alterar a rotina desse sistema cuja organização na maioria das vezes não atende às reais necessidades dos projetos escolares e até as compromete torna-se obrigação daqueles e daquelas que aceitaram os desafios da gestão da escola pública. Afinal, "são as pessoas que assumem os processos sociais institucionalizados" (HORTON; HUNT, 1980), que colocam as normas da instituição em prática, especialmente nas regiões periféricas da cidade, onde as condições de vulnerabilidade social proporcionam desafios diferenciados, senão ainda maiores, conforme demonstram pesquisas recentes ${ }^{2}$.

A discussão sobre vulnerabilidade social remete imediatamente à questão da pobreza. No entanto, ela não exaure todo o conceito. Envolve dificuldades relativas às condições de moradia, à infraestrutura básica, ao acesso a equipamentos de atenção à saúde, que são parcos e prestam serviços de baixa qualidade. Nos locais vulneráveis das periferias de São Paulo, o acesso ao lazer e à cultura é praticamente nulo, não fosse pela existência dos Centros Educacionais Unificados (CEUs), que promovem algumas atividades esportivas abertas à comunidade, entre elas sessões de cinema e uns poucos

BAUDELOT, Christian et al. Les effets de l'éducation: rapport à l'intention du piref. Paris: École Normale Supérieure, 2004, p.19.

Ver BATISTA, Antônio Augusto Gomes; CARVALHO-SILVA, Hamilton Harley; Família, escola e território vulnerável, Cenpec, 2013 e AÇÃO EDUCATIVA. Educação e desigualdades na cidade de São Paulo. São Paulo: Ação Educativa, 2013. 
espetáculos teatrais. Na região próximo à escola na qual se desenvolveu a experiência aqui registrada há também uma Fábrica de Cultura à qual os moradores da região podem ter acesso.

de é uma noção multidimensional, na medida em que afeta indivíduos, unidades em planos distintos de seu bem-estar, de diferentes formas $e$ Entre os fatores que compõem as situações de vulnerabilidade social estão: u desproteção ante as mudanças originadas em seu entorno, o desamparo los cidadãos pelo Estado; a debilidade interna de indivíduos ou famílias para Ianças necessárias a fim de aproveitar o conjunto de oportunidades que se nsegurança permanente que paralisa, incapacita e desmotiva no sentido de gias e realizar ações com o objetivo de lograr melhores condições de vida apud SEADE, 2010).

A gestão compartilhada de uma escola localizada no extremo leste da cidade numa região de alta vulnerabilidade social, com Índice de Desenvolvimento Humano (IDH) de 0,460, categorizado como grupo 6 na classificação do Índice Paulista de Vulnerabilidade Social ${ }^{4}$ e índice de Vulnerabilidade Juvenil de 80 pontos, numa escala de 100, é desafiante, como em qualquer outra escola. Nesse território prevalece a baixa concentração de renda e escolaridade, e há questões sociais que poderiam surpreender pelas condições desumanas em que sobrevivem algumas famílias. Essa situação torna a ação educativa escolar mais complexa, exigindo muita sensibilidade e um olhar essencialmente humanizado, de um gestor preocupado em oferecer uma educação que valorize o potencial existente, resgatando a dignidade humana de cada família e das crianças.

A experiência de gestão escolar compartilhada em implantação propõe ações integradas e integradoras, no sentido exposto por Heloisa Lück em que

USSO, G. Vulnerabilidad social: nociones e implicancias de políticas para latinoamerica a inicios del glo XXI. In: SEMINÁRIO INTERNACIONAL LAS DIFERENTES EX- PRESIONES DE LA VULNERABILIDAD EN MéRICA LATINA y EL CARIBE. Anais... Santiago do Chile: Cepal; Celade, 2001.

rupo 6 (vulnerabilidade muito alta): 993.326 pessoas (9,5\% do total). No espaço ocupado por esses atores censitários, o rendimento nominal médio dos responsáveis pelo domicílio era de $R \$ 349,00$ $73,9 \%$ deles auferiam renda de até três salários mínimos. Em termos de escolaridade, os chefes de omicílios apresentavam, em média, 4,4 anos de estudo, 82,3\% deles eram alfabetizados e 20,3\% mpletaram o ensino fundamental. Com relação aos indicadores demográficos, a idade média os responsáveis pelos domicílios era de 39 anos e aqueles com menos de 30 anos representavam $5,6 \%$. As mulheres chefes de domicílios correspondiam a 27,1\% e a parcela de crianças de 0 a 4 anos quivalia a $13,1 \%$ do total da população desse grupo. 
a ação do corpo técnico-administrativo deve ser não só integrada mas também integradora.

Para tanto, deve pautar-se por atitudes, direções e objetivos comuns, o que estabelecerá a coerência interna necessária para se garantir a unidade preconizada. [...] um objetivo comum do corpo técnico-administrativo é a criação de condições favoráveis ao máximo desenvolvimento das potencialidades da comunidade escolar, promovida num ambiente de cooperação, reciprocidade, em que todos os participantes do processo educativo atuam como companheiros que têm muito a contribuir com suas percepções, experiências, conhecimentos

e habilidades na análise e decisão sobre as problemáticas do dia a dia do processo educativo. Mediante a análise e decisão conjunta dessas problemáticas promover-se-ia o desenvolvimento de potencialidades desejado (LÜCK, 2008, p. 32-33).

A experiência de gestão escolar compartilhada em implantação propõe a superação do poder individual e a promoção da inter-relação da equipe técnica entre si, entre funcionários, professores, alunos e comunidade em geral, implantando a autonomia escolar de fato ${ }^{5}$. 0 diálogo deve ser permanente, para vencer os desafios diários e, simultaneamente, proporcionar relações mais horizontalizadas, rompendo com a ideia arcaica da administração autocrática $^{6}$, cujo poder está centralizado nas mãos do diretor da escola.

[...] é importante que a participação seja entendida como um processo dinâmico e interativo que vai muito além da tomada de decisão, uma vez caracterizado pelo interapoio na convivência do cotidiano da gestão educacional, na busca, por seus agentes, da superação de suas dificuldades e limitações do enfrentamento de seus desafios, do bom cumprimento de sua finalidade social e do desenvolvimento de sua identidade (LÜCK, 2011, p. 30).

Propõe, ainda, um trabalho construído eminentemente em espaços coletivos, em que todos se associem e cooperem em todo o processo, analisando as situações, discutindo o assunto, tomando decisões sobre encaminhamentos e atuando. Um verdadeiro processo de mobilização da ação construtiva conjunta, de corresponsabilidade partilhada e orientada pela vontade coletiva de alterar a realidade existente (LÜCK, 2011), proporcionando educação com a máxima qualidade possível no contexto escolar e socioespacial existente. Sabedora de que não se pode atribuir um caráter mágico e ilusório a esse processo de construção de uma escola que se diferencie nos modos de agir, mas que persiga seus objetivos de ensinar e de formar cidadãos que possam atuar no meio em que vivem. Contudo, é preciso admitir que surgem problemas

5 Entendemos que a autonomia escolar de fato corresponde a plenas possibilidades de atuação da escola dentro do sistema, sem interferências externas e regulatórias dos processos internos, nos quais devem estar envolvidos todos os membros da comunidade escolar.

6 A administração autocrática [...] centraliza as decisões e todo o poder nas mãos da diretora ou do diretor, acaba gerando uma sobrecarga de trabalho para os mesmos e, por conseguinte, estabelece relações conflituosas no âmbito escolar, o que contribui para gerar o insucesso dos alunos (ROMÃO; PADILHA, 2001, p. 92). 
no percurso de implantação. Há relações hierárquicas, hierarquizadas e de poder entre os diversos segmentos que interferem muito na consecução dos objetivos de uma relação diferenciada.

Infelizmente não é incomum que as orientações e reflexões propostas pela direção educacional adquiram um significado diferenciado do desejado ou até supervalorizado por alguns receptores, pelo simples fato de ser o emissor figura responsável na condução da gestão que, supostamente, detém o poder máximo na gestão da escola. "O famoso enunciado de Gertrude Stein 'Uma rosa é uma rosa"” (HORTON; HUNT, 1980) exemplifica bem o que acontece na escola, quando os diferentes papéis se confrontam, sem que nesse confronto haja, necessariamente, o conflito, já que professor é professor, diretor é diretor, aluno é aluno e assim sucessivamente, e cada qual ocupa sua posição nesse espaço. A ilusão e resquícios de uma história da gestão autocrática, que supervalorizam posições na estrutura organizacional, precisam ser transformados, já que a construção coletiva requer outras formas de relacionamento, não aquelas pautadas no poder ilusório, distante do poder real, e necessário, de que cada um é possuidor na execução de sua função.

Não se trata de desconsiderar as relações hierárquicas e de poder existentes nas relações no ambiente escolar, mas, ao contrário, de vislumbrar, criticamente, que essas relações podem ser diferentes e enfrentar o desafio de promover outro modelo de gestão escolar, que se proponha a enfrentar os conflitos naturais do processo, em que o compartilhamento de ideias, responsabilidades e problemas promova a busca de soluções conjuntas e sob a responsabilidade compartilhada entre todos, em que cada um assume uma parcela desse todo (FREIRE, 1979; LÜCK, 2011).

Estabelecendo uma analogia à citação de Horton e Hunt, "Uma rosa é uma rosa", poderíamos imaginar os diversos agentes sociais da escola compondo um jardim em que rosas e outras flores, plantas e arbustos convivem e em conjunto compõem um jardim colorido e perfumado, sem que com isso uma planta deva se sobrepor à outra. Dessa forma, compreende-se que a gestão da escola, centrada na figura do diretor, é desnecessária, uma vez que esse agente, assim como os outros, deve cumprir sua função e que, no conjunto, compõem o belo jardim. Mudança na tradicional função exercida pelo diretor? Sim, até certo ponto, pois cabe ao diretor de escola, entre outras, a função de mobilizar, articular, liderar, mediar e coordenar pessoas e processos gerais de trabalho necessários para evitar ações paralelas ou em duplicidade, relações interpessoais nocivas ao bom andamento das diretrizes do trabalho e conflitos gerados pela - necessária - divisão de trabalho. 
Mas cabe ressaltar enfaticamente que, sozinho, um diretor de escola não é suficiente para o sucesso das implantações de uma boa gestão. Não se trata de uma monarquia educacional e sim da implantação da gestão democrática e participativa na instituição em prol do futuro promissor da educação nessas regiões vulneráveis.

Implantar um projeto político-pedagógico que seja construído no interior da escola, com a participação de todos, ainda é um sonho a ser realizado plenamente? ${ }^{7}$ Um sonho perseguido insistentemente há anos, pois envolver a todos não é tão simples, mas é possível e realizável. "Aumentando-se o poder de decisão das pessoas, aumenta-se o poder de ação, de aprendizagem e de transformação das práticas e, portanto, o poder da educação" (LÜCK, 2011, p. 121).

A complexidade das discussões e da compreensão de todos e de cada um sobre a realidade escolar, sobre o contexto social em que vivem e sobrevivem muitos alunos, sobre as necessidades educativas e sociais da comunidade em que a escola está inserida é distinta. Compreender o contexto social de vulnerabilidade em que está situada a unidade escolar e nele encontrar as possibilidades de atuação muitas vezes não é tão simples. Há processos vividos no cotidiano que implicam sofrimentos psicológicos pelo qual passam os professores e funcionários diante das misérias do mundo encontradas em situações no ambiente escolar, onde os sofrimentos sociais (BOURDIEU, 2008a) dos alunos ficam em evidência.

A lógica escolar, muitas vezes reprodutora da lógica social, na maioria das vezes não se coaduna com a realidade do contexto escolar em regiões de vulnerabilidade social. Profissionais no interior da escola não possuem a mesma visão que a comunidade, pais e alunos que observam a realidade de outro ponto de vista. E como afirma Leonardo Boff (1997), “Todo ponto de vista é a vista de um ponto", de modo que conciliar diferentes pontos de vista a fim de atender às necessidades educacionais e sociais dos alunos tornase um processo complexo, longo e difícil, pois há muitas interferências, de diversas naturezas: psicológicas, materiais, culturais, de condições práticas e objetivas de sobrevivência e alimentação, que se confrontam com as leituras interpretativas dos educadores e profissionais da escola e com as interferências de natureza burocrática e administrativa do sistema de ensino.

A gestão democrática não é processo simples, de curtíssimo prazo, mas também não é tão complexo ou irrealizável, de prazo interminável (ROMÃO; PADILHA, 2001, p. 96). 
Perceber como essas lógicas atuam em seus respectivos campos significa compreender que escola e família promovem a socialização sob enfoques diferenciados, mas não menos importantes diante um do outro (THIN, 2006). Trata-se de admitir que a escola atua na lógica didática e escolar, em que prevalece a cultura escolar baseada na cultura social, enquanto a família atua sob a lógica da socialização familiar com ações pedagógicas familiares próprias, calcadas em valores próprios, construídos com base no capital cultural, econômico e social de que dispõe (BOURDIEU, 1979).

Nessa relação que a escola e seus profissionais estabelecem com o território vulnerável, nem sempre reina a paz, pois diferentes enfoques e lógicas podem provocar confrontos e submissões de ambas as instituições: escola e família. A lógica da cultura escolar, legitimada por sua posição no espaço social, é, muitas vezes, supervalorizada pela comunidade, que nem sempre se sente acolhida e valorizada, porém alimenta o sonho da escolarização como possibilidade de um vir a ser, em que as condições materiais de existência da família poderão se transformar, pois entendem que "a escola é mais do que uma possibilidade de aprender, é a única saída para se ter "uma vida melhor'. O estudo [...] confere um lugar social, dá um nome e uma identidade" (LOMONACO; GARRAFA, 2009, p. 32).

As interferências provocadas pela organização formal do sistema na rotina da escola podem dificultar, inviabilizar, senão comprometer em grande medida a efetivação de propostas interessantes e inovadoras no trabalho da escola, pois oriundas da estrutura organizacional do sistema educacional, que deprecia a autonomia escolar, prejudicando a construção do sentimento de autoria e de responsabilidade coletivas (LÜCK, 2011), que muitas vezes é arduamente construído no espaço escolar.

Juntamente com as outras interferências advindas da realidade e do contexto do território em que está inserida, para as quais deve responder com ações efetivas que promovam a qualidade social da educação naquele contexto, a escola deve enfrentar todos os desafios postos à sua frente, dentro de seus limites, mas essencialmente considerando suas possibilidades de ação em sua área de competência, remetendo o que não lhe compete aos órgãos e instituições sociais responsáveis.

A remoção anual de professores é um dos fatores que pode comprometer a implantação de projetos específicos e de interesse das comunidades, compreendendo sempre que a construção e efetivação de projetos políticopedagógicos devem, obrigatoriamente, atender à demanda local, orientando- 
se nas diretrizes da política educacional nacional e local. Mas, principalmente, compreendendo-se que o foco central é a necessidade local, a participação de todos e com toda certeza a implantação sob a responsabilidade daqueles e daquelas que constroem e reconstroem diariamente o projeto políticopedagógico no processo.

Dessa forma, observa-se que, embora seja considerado como direito dos profissionais da educação a remoção anual de unidade de trabalho, esse processo interfere enormemente na consecução dos planos elaborados, pois a mudança de equipe requer adequações, atualizações e contextualizações que demandam o escasso tempo de trabalho de todos, comprometendo assim a execução de fato das ações planejadas.

Apreender a realidade local, o percurso da escola, dos alunos e daqueles profissionais envolvidos e que permanecem na escola exige dos novatos dedicação, disposição e um tempo que na organização escolar não está disponível, embora seja um tempo essencial.

Um dos grandes desafios na concretude dos projetos refere-se justamente aos elementos organizadores que conformam e definem os tempos e espaços no ambiente escolar (FRAGO, 1995, p. 69). Os tempos e espaços escolares, na herança da cultura escolar, ou culturas escolares, como diria Frago, em que vige o sistema atual, não privilegiam o tempo do pensamento, da elaboração, da reflexão e avaliação no planejamento e replanejamento, e assim sucessivamente, numa práxis reflexiva em que ação e reflexão caminhem e sejam aliadas da ação intencional, pensada e refletida coletivamente.

Implantar projetos e no mesmo espaço e tempo acolher os novos profissionais, os novos pais, mães, responsáveis pelos alunos e os novos alunos torna a dinâmica exaustiva e de difícil conciliação. Uma variedade de ações em tempos simultâneos que caracterizam o tempo institucional e organizativo da escola delimita as relações que se estabelecem nesse ambiente, num esquema formal e numa estrutura que não se revelam neutras, mas, ao contrário, determinam "supostos psicopedagógicos, valores e formas de gestão, um tempo a interiorizar e aprender" (ESCOLANO, 1992 ${ }^{\circ}$, p. 56 apud FRAGO, 1995, p. 72).

É como trocar os pneus do carro em movimento. Promover o acolhimento àqueles que chegam, a fim de que compreendam, ainda que de modo limitado

ESCOLANO, Agustín. Tiempo y educación: notas para una genealogía del almanaque escolar. Revista de Educación, Madrid, n. 298, p. 55-70, mai./ago. 1992. 
pela ausência da participação nos processos, o percurso percorrido e vivido pela escola9 e se integrem ao trabalho é dever daqueles que já estão há mais tempo na unidade e requer destes o esforço de buscar registros e apoios de memória para fazê-lo. Ou seja, é necessário que se conciliem os tempos e percursos individuais e institucionais, pessoais e coletivos socialmente construídos e instituídos formalmente na escola, a fim de que se relacionem com outros tempos sociais, nos quais estão envolvidos todos aqueles que fazem parte do processo de escolarização.

Resumidamente, pode-se concluir, conforme analisa Frago, que os aspectos legais, teóricos e escolares se inter-relacionam e influenciam reciprocamente, mas que nem sempre coincidem temporalmente,

[causando] descontinuidades e rupturas, inércias e persistências, a diversidade de práticas, os elementos determinantes de tal diversidade e, por último, a tripla natureza da distribuição do trabalho escolar como meio disciplinar, mecanismo de organização e racionalidade curricular e instrumento de controle externo, ou seja, como aspecto básico condicionado por e condicionante da cultura escolar (FRAGO, 1995, p. 74).

Tornar concreto o sonho de uma escola que promova a qualidade social da educação e apreender que a "construção de uma escola de qualidade é, ainda hoje, sem dúvida um dos nossos maiores desafios" (FARIA FILHO; VIDAL, 2000, p. 32), exigindo esforços de todos e, nesse percurso, a criatividade ${ }^{10}$ é sempre uma aliada na elaboração de novas ideias que surgem como possibilidades de um novo caminho a ser trilhado enquanto é construído.

A concretude das reuniões semanais da equipe técnica ${ }^{11}$ representa um desafio semanal pela simultaneidade dos acontecimentos rotineiros, já que a escola se encontra em pleno funcionamento quando se destina um horário para a discussão do trabalho e dos projetos em andamento. Não é sem algum sofrimento que se consegue realizar essa reunião semanal que, invariavelmente, sofre diversas interrupções. Mas a persistência e a valorização desse espaço de participação coletiva, considerando-o privilegiado na gestão compartilhada, integrada e integradora, na tomada de decisões, tem

9 Compreenda-se escola como todo o conjunto amplo que envolve desde a estrutura física, mas que envolve essencialmente as pessoas, sejam elas profissionais da educação nos diversos níveis e funções, os alunos, pais, mães e outros responsáveis pelos alunos.

10 "Cada vez mais a criatividade do professor é elemento fundamental no processo educativo devido à necessidade de atualização da escola e à demanda de uma sociedade em permanente transformação" (MOURÃO; MARTíNEZ, 2006).

${ }_{11}$ Considera-se equipe técnica nas escolas municipais de São Paulo o diretor, assistentes de direção - em geral dois profissionais - e coordenadores pedagógicos - em geral também dois. Na escola em que atuo incluímos a secretária da escola também. 
proporcionado avanços, demonstrando que é uma "estratégia fundamental na determinação das ações e dos propósitos educacionais” (LÜCK, 2011, p. 105), e que representa um caminho possível e um facilitador no processo, pois permite reflexões conjuntas, rompendo com a ótica individualista (LÜCK, 2011), auxiliando na tomada de decisões mais acertadas, pois é fundamental a lucidez e percepção de que erros e acertos fazem parte dos diversos processos e tornam o trabalho coletivo menos desgastante. Saber que construímos soluções provisórias nos proporciona a oportunidade de atenção e reflexão constante e de manter sempre a criatividade ativa.

Obviamente, a gestão compartilhada na escola não se resume às reuniões semanais da equipe técnica e não se concretiza sem a participação de todos os envolvidos. Nesse sentido, a promoção de formação permanente envolvendo não somente os professores, mas todos os outros funcionários, agentes escolares e auxiliares técnicos de educação - inspetoria de alunos e secretaria - também se apresenta como um desafio e revelou-se uma possibilidade concreta com a realização de reuniões também semanais durante todo o ano de 2012. O protagonismo dos funcionários em suas respectivas funções, a partir da compreensão da responsabilidade que é compartilhada por todos e das responsabilidades específicas e relativas a cada um no exercício da função pública num espaço educativo, representou um grande avanço no dia a dia e na solução de pequenos problemas nas áreas de responsabilidades desses funcionários.

A possibilidade de participação, realização de estudos e reflexões, de proposição de ideias e sugestões, a concretização de planos de ação elaborados por eles representaram uma valorização dos funcionários que, ao longo da história sempre revelaram algum descontentamento pela posição subalterna que julgavam ter dentro da escola. A compreensão do valor do trabalho e da função que cada um exerce, da responsabilidade e do compromisso de agente público permitiu a mudança de postura nas relações interpessoais. Os funcionários foram envolvidos em produções do projeto político- pedagógico, sendo os responsáveis por organizar parte da exposição que se referia à respectiva área de atuação - inspetoria, secretaria, limpeza - na Mostra Anual de trabalhos de 2012, protagonizando a ação pedagógica, aliando-a a sua ação rotineira, não menos pedagógica, buscando arquivos da história e memória da escola no acervo documental existente e realizando pesquisas de campo a fim de obter uniformes antigos, de alunos e funcionários, apetrechos que fizeram parte da história da escola e até construindo uma maquete comparativa do primeiro prédio erguido em 
1975 e o atual, reformado em 1999.

Promover o protagonismo de todos, alunos, professores e funcionários, tem sido um desafio. Objetivo galgado desde 2007, vem sendo conquistado paulatinamente com ações mais ou menos incisivas, permanentes e inovadoras. Incentivar o protagonismo dos alunos por meio de projetos em que participam ${ }^{12}$ optativamente como Monitores de Informática Educativa, Monitores de Sala de Leitura, Monitores de Recreio Dirigido (Projeto Mundo Mágico) e nos quais vivenciam processos de formação permanente, sendo os autores de sua prática, realizando pesquisas, produzindo roteiros, regras e modos de organização grupal representam desafios e concretudes diante da realidade em que possibilidades estão postas a partir da disposição para a realização do novo. A percepção de que se tornam "um coletivo atuante, cujos deveres emanam dele mesmo, a partir de sua maturidade social, e se configuram em sua expressão e identidade, que se renova e se supera continuamente" (LÜCK, 2011, p. 56), tem promovido a participação, ano a ano, de um número de cada vez maior de alunos, pois o boca a boca entre eles se tornou o marketing da informação no processo de inscrição dos interessados.

A perspectiva do protagonismo infanto-juvenil pleno, do ponto de vista que afirma BRENER (s.d.), em que "o jovem é tomado como elemento central da prática educativa, que participa de todas as fases desta prática, desde a elaboração, execução até a avaliação das ações propostas”, é uma realidade desconhecida no tempo de permanência escolar dos alunos na escola de ensino fundamental. Trabalha-se para prospectar o protagonismo pleno desses alunos no mundo, em ações sociais cidadãs das quais a escola de ensino fundamental, seus professores e funcionários, não serão testemunhas oculares e quiçá obterão alguma notícia.

Realizar discussões acerca das atribuições e responsabilidades de um aluno que possa ser Representante de Sala, promover o processo eleitoral para defini-lo e posteriormente promover sua participação em reuniões com a equipe gestora é um exercício instigante e prazeroso, que, no entanto, gera um novo desafio, que é ser suficiente para atender às demandas e expectativas dos alunos, inquietos e ávidos em contribuir para a construção de uma

12 Os sentidos da participação são múltiplos, uma vez que as significações (simples) trazem em si a incumbência de representar a subjetividade que possam adquirir tais significados, em determinados contextos sociais de relações objetivas, transformados em ações efetivas. De modo que se optou pela participação como uma política educacional que privilegia a mobilização e o envolvimento dos alunos nos projetos de interesse deles. 
escola melhor. Resumindo, não temos pernas para dar conta de mais esta atividade, mas os esforços têm sido envidados, diante das possibilidades, e ano a ano garantimos a participação desse grupo de alunos em reuniões, corresponsabilizando-os em atividades nas quais representam o apoio à gestão na consecução de diversas tarefas.

Não se trata de transformá-los em mão de obra barata, mas, ao contrário, de colocá-los diante da realidade das demandas da gestão escolar e das possibilidades contributivas que possam trazer. Colocando-os na dinâmica interativa da escola, em que sua atuação participativa trará contributos ao processo e ao próprio desenvolvimento pessoal, como ser humano e cidadão (LÜCK, 2011, p. 61). É vê-los passar de agentes passivos a agentes ativos.

Certamente que esse processo não se passa sem dores, conflitos e oportunidades de reflexão, pois não raras vezes os alunos colocam em questão o sistema escolar, os tempos e espaços de aprendizagem, posturas inesperadas de professores e funcionários, obrigando a equipe gestora a refletir e (re)pensar a escola atual.

A possibilidade de desvincular saber de poder, no plano escolar, reside na criação de estruturas horizontais em que professores, alunos e funcionários formem uma comunidade real. É um resultado que só pode porvir de muitas lutas, de vitórias setoriais, derrotas, também. Mas, sem dúvida, a autogestão da escola pelos trabalhadores da educação incluindo os alunos - é a condição de democratização escolar (TRAGTENBERG, 2002, p. 16).

Bernard Charlot (2009, p. 92) afirma que: “A participação do aluno na sala de aula e fora dela é tão importante quanto a sua categoria social ou sexual para se entender o que está acontecendo na escola”. Isso fica evidente na singeleza e simplicidade característica da idade dos alunos no ensino fundamental, que muitas vezes trazem questionamentos profundos, assim como surpreendem com análises inesperadas da realidade, demonstrando e trazendo à tona saberes escolares, transformados em saberes cotidianos e vice-versa.

De tudo que se afirma e se demonstra neste artigo, o essencial é esclarecer a existência de escolas públicas em que se prima pela qualidade do trabalho, em que se vislumbram possibilidades diante das dificuldades e das condições objetivas de existência de muitos alunos e suas famílias nos territórios vulneráveis. Que sonhos são permitidos onde a exclusão e os altos índices de vulnerabilidade social estão escancarados para que todos possam ver. Onde se reconhece as potencialidades daqueles e daquelas que vivem em precárias condições de vida. Onde a vinculação entre as condições objetivas de existência pode ser alterada por oportunidades de se conscientizar da 
realidade de exclusão social e assim transformá-la, alternativa que, segundo Bourdieu e Passeron (2008b), seria a única para romper com o processo de reprodução das desigualdades sociais, por meio das desigualdades escolares legitimadas. Ou, como propõe Bernard Charlot (2009, p. 95), temos que refletir: "Até que ponto as nossas escolas induzem os alunos a ter uma atividade intelectual, os introduzem em universos novos, constroem outras formas de se relacionar com o mundo?".

Arriscaria uma resposta: muito pouco se faz, e é justamente aqui que entra o altruísmo, não no sentido de benevolência, abnegação ou filantropia. Ao contrário, altruísmo no sentido de empenho e dedicação, acreditando-se que é humanamente possível, que muito pode ser feito e que iniciativas têm sido tomadas pelas diversas escolas do país em busca de se construir uma escola diferente daquela existente, em que os resultados provocam frustrações e desânimo nos profissionais da educação, dificultando a realização de trabalhos diferenciados que atendam às reais necessidades daquelas populações em territórios cuja vulnerabilidade social em que se encontram apresentam demandas também diferenciadas para a instituição escolar. 


\section{Dreams and materialities in territories of latent social vulnerability: altruism in school administration}

Abstract: The article aims at reporting a management practice developed in a municipal school on the outskirts of São Paulo, a region of high social vulnerability. The experiment aimed at including both all school servants and the local community in the educational process. This text examines the implanting of a management proposal different from the traditional one, which goes precisely against some rules that, one esteems, make the success of the education management as a whole unfeasible. It shows aspects that portray discrepancies between schools and communities. It emphasizes that in order to accomplish a non-traditional collective task in a vulnerable territory school one needs a concatenated and proactive team in pursuit of good interpersonal relationships. It tries to show that it is possible to build and manage education aiming at people's dignity.

Keywords: Democratic management. Protagonism. Social vulnerability. 
AÇÃO EDUCATIVA. Educação e desigualdades na cidade de São Paulo. 1. ed. São Paulo: Ação Educativa, 2013. (Em Questão, 8).

AZANHA, José Mário Pires. Cultura escolar brasileira. In: Educação: temas polêmicos. São Paulo: Martins Fontes, 1995, p. 67-78.

BATISTA, Antonio Augusto Gomes; CARVALHO-SILVA, Hamilton Harley de. Família, escola, território vulnerável. São Paulo: Cenpec, 2013.

BOFF, Leonardo. A águia e a galinha: uma metáfora sobre a condição humana. Petrópolis: Vozes, 1997.

BOURDIEU, Pierre. [Les trois états du capital culturel, publicado originalmente em Actes de la Recherche em Sciences Sociales, Paris, n. 30, p. 3-6, nov. 1979.] Os três estados do capital cultural. Trad. Magali Castro. In: NOGUEIRA, Maria Alice; CATANI, Afrânio (Orgs.). Escritos de educação. Petrópolis: Vozes, 2008, p. 71-79.

[com contribuições de A. Accardo et al]. A miséria do mundo. 7. ed. Trad. Mateus S. Soares Azevedo et al. Petrópolis: Vozes, 2008a.

; PASSERON, Jean Claude. A reprodução. 3. ed. Trad. Bairão Reynaldo. Petrópolis: Vozes, 2008b. 275 p.

BRENER, Branca Sylvia. 0 que é protagonismo juvenil? s.d. Disponível em: 〈http://www.promenino.org.br/Servicos/Biblioteca/o-que-e-protagonismojuvenil>. Acesso em: 17 abr. 2014.

CHARLOT, Bernard. A escola e o trabalho dos alunos. Sísifo - Revista de Ciências da Educação, n. 10, p. 89-96, set./dez. 2009.

DUBET, François. 0 que é uma escola justa? A escola das oportunidades. Trad. Ione Ribeiro Valle. São Paulo: Cortez, 2008. 119 p.

FARIA FILHO, Luciano Mendes de; VIDAL, Diana Gonçalves. Os tempos e os espaços escolares no processo de institucionalização da educação escolar primária no Brasil. Revista Brasileira de Educação, Rio de Janeiro, n. 14, p. 19-34, maio/ago. 2000.

FRAGO, Antonio Viñao. Historia de la educación y historia cultural: possibilidades, problemas, cuestones. Revista Brasileira de Educação, Rio de Janeiro, p. 63-82, set./dez. 1995. 
FREIRE, Paulo. Educação e mudança. 24. ed. Rio de Janeiro: Paz e Terra, 1979. HORTON, Paul Burleigh; HUNT, Chester L. Instituições sociais. In: Sociologia. São Paulo: McGraw-Hill, 1980.

LOMONACO, Beatriz Penteado; GARRAFA, Thais Christofe. A complexidade da relação escola-família em territórios vulneráveis. Cadernos Cenpec, São Paulo, n. 6, p. 27-38, 2009.

LÜCK, Heloísa. Ação integrada: administração, supervisão e orientação educacional. 26. ed. Petrópolis: Vozes, 2008.

A gestão participativa na escola. 10. ed. Petrópolis: Vozes, 2011.

MARTINS, Angela Maria. Autonomia e gestão da escola pública: aportes para uma discussão. In: OLIVEIRA, Dalila Andrade; ROSAR, Maria de Fátima F. (Orgs.). Política e gestão da educação. Belo Horizonte: Autêntica, 2002.

MOURÃO, Renata Fernandes; MARTínEZ, Albertina Mitjáns. A criatividade do professor: a relação entre o sentido subjetivo da criatividade e a pedagogia de projetos. Psicologia Escolar e Educacional, Campinas, v. 10, n. 2, dez. 2006.

ROMÃO, José Eustáquio; PADILHA, José Roberto. Diretores escolares e gestão democrática da escola. In: GADOTTI, Moacir; ROMÃO, Joé Eustáquio. Autonomia da escola - princípios e propostas (Orgs.). 4. ed. São Paulo: Cortez: Instituto Paulo Freire, 2001, p. 91-102. (Guia da Escola Cidadã, 1).

SEADE. Espaços e dimensões da pobreza nos municípios do estado de São Paulo. 2010. Disponível em: 〈http://www.iprsipvs.seade.gov.br/view/index. php?prodCod=2〉. Acesso em: 20 mar. 2014.

THIN, Daniel. Para uma análise das relações entre famílias populares e escola: confrontação entre lógicas socializadoras. Revista Brasileira de Educação, Rio de Janeiro, v. 11, n. 32, p. 211-225, maio/ago. 2006.

TRAGTENBERG, Maurício. Relações de poder na escola. In: OLIVEIRA, Dalila Andrade; ROSAR, Maria de Fátima F. (Orgs.). Política e gestão da educação. Belo Horizonte: Autêntica, 2002.

RECEBIDO: Fevereiro de 2014.

APROVADO: Março de 2014. 